\title{
Pharmacological investigations of neuroprotective potential of Centella lujica supplement on sleep deprivation-induced anxiety-like behaviour in mice
}

\author{
Anthony T. Eduviere ${ }^{1 *}$, Prosper E. Awhin ${ }^{2}$, Kesiena E. Edje ${ }^{1}$, Lily O. Otomewo ${ }^{1}$, \\ Emuesiri G. Moke ${ }^{1}$, Adrian I. Omogbiya ${ }^{1}$, Oghenemaro P. Idiowa ${ }^{1}$
}

\begin{abstract}
${ }^{1}$ Department of Pharmacology and Therapeutics, ${ }^{2}$ Department of Medical Biochemistry, Faculty of Basic Medical Sciences, Delta State University, Abraka, Delta State, Nigeria
\end{abstract}

Received: 25 August 2021

Revised: 17 September 2021

Accepted: 22 September 2021

\section{*Correspondence:}

Dr. Anthony T. Eduviere,

Email: tonyeduviere@yahoo.com

Copyright: (C) the author(s), publisher and licensee Medip Academy. This is an open-access article distributed under the terms of the Creative Commons Attribution Non-Commercial License, which permits unrestricted non-commercial use, distribution, and reproduction in any medium, provided the original work is properly cited.

\begin{abstract}
Background: Sleep deprivation has often been implicated in several neurological disorders. Centella lujica is a psychoactive herb with medically-beneficial therapeutic potential. The current study sought to evaluate the neuroprotective effect of Centella lujica supplement in experimental animals.

Methods: Sleep deprivation in mice was done using the multiple platforms over water model.

Results: Upon treatment with Centella lujica supplement, the parameters of anxiety-like behaviour induced by sleep deprivation were found to be significantly diminished in comparison to the sleep deprived animals.

Conclusions: Centella lujica treatment significantly decreased hyper locomotion, and anxiety-like behaviour caused by sleep deprivation.
\end{abstract}

Keywords: Centella lujica, Locomotion, Anxiety, Sleep deprivation

\section{INTRODUCTION}

Sleep is a dynamic state characterized by diminished awareness and responsiveness. ${ }^{1,2}$ Though its total function still remains elusive, studies have shown that it is necessary for neurological, somatic and psychological health throughout life and its deprivation leads to a drastic deterioration in cognitive functions, alertness, learning and memory as well as mood disorders. ${ }^{3-5}$ Prolonged deprivation of sleep, especially rapid eye movement sleep, is often associated with anxiety, aggressive behavior, memory impairment, oxidative stress and mania. ${ }^{6-11}$ Several studies have highlighted the connection between sleep deprivation and mania, with each concluding that lack of sleep is key to the development of a manic-like phenotype (e.g. anxiety) in animals sleep deprived for more than 24 hours.

According to Turk and his colleagues, anxiety is a sensation of fear and uneasiness which is usually generalized as an overreaction to a situation that is only individually perceived as frightening. ${ }^{12}$ Also, anxiety is usually experienced when a person believes he is unprepared and lacks the needed skills to cope with an anticipated event. Usually, a significant level of anxiety can be proper, but when experienced regularly; the individual may be diagnosed with anxiety disorder. Some signs and symptoms of anxiety or anxiety disorders are feelings of fear or dread, trembling, restlessness, agitation, fatigue, muscle tension, dizziness, perspiration and shortness of breath. 
Anxiety has been previously described as one of the most debilitating consequences of sleep deprivation. This effect was first reported by Dement, in the foremost experiment with rapid eye movement (REM) sleep deprivation in humans. ${ }^{13}$ More recent experiments outlined other symptoms such as: feeling nervous, restless or tensed, having increased heart rate (tachycardia), breathing rapidly (hyperventilation), sweating, feeling weak or tired, trouble concentrating, having trouble sleeping, experiencing gastrointestinal (GI) problems, having difficulty and controlling worry. ${ }^{14}$ In the central nervous system (CNS), the major neurotransmitters involved in anxiety-like symptoms appear to be serotonin, norepinephrine, gamma-amino butyric acid (GABA) and dopamine. Others such as corticotrophin-releasing factor may be involved, while peripherally, the autonomic nervous system (ANS), especially the sympathetic nervous system, mediates many of the symptoms. Ethno medicinal substances are commonly used by locals in Nigeria as alternatives to existing clinically available drugs for management of anxiety related disorders.

Gotu kola (Centella lujica), belonging to the Apiaceae family, is a perennial medicinal herb found in Nigeria. As with the popular congener Centella asiatica found in South-east Asia and India, this herb has been shown to have certain health benefits. Saponins (or triterpenoids), the primary constituent of gotu kola are mainly believed to be responsible for its wide and therapeutic actions. Various studies have reported that it serves as a potent brain tonic hence it is famously dubbed as food for the brain and it has been shown to possess remarkable potency in treating senile decay and loss of memory. ${ }^{15,16}$ A study by Cooper and $\mathrm{Ma}$ demonstrated that the gotu kola species exhibit widespread neuroprotection via various mechanisms such as reducing oxidative stress and preventing the formation of amyloidal plaques in Alzheimer disease (AD) patients. ${ }^{17}$ Furthermore, gotu kola was defined to possess CNS effects in India literature as a stimulatory-nervine tonic, immune booster, and an intelligence promoting herb.

Studies have also prompted its use in reduction of high blood pressure, slowing down of the aging process, acceleration of wound healing as well as relief of inflammation and as an antioxidant. ${ }^{18,19}$ It was also seen to be helpful in treating ulcers and help protect the body against toxins. Several patients with circulatory irregularities like venous insufficiency and varicose veins, chronic venous insufficiency, infectious hepatitis, jaundice, dysentery, colds, bronchitis, asthma, syphilis and urinary tract infections were seen to benefit from this herb though the mechanism of these actions are unknown. ${ }^{20}$ Other than being food for the brain, it is also used to increase libido and useful in helping to reverse some cases of partial impotence; in some, it improves eye sight, improves cognition and also acts as a sedative. ${ }^{20}$ Therefore, based on the reported neuroprotective effect of the gotu kola species, the present study seeks to evaluate the effect of Centella lujica supplementation on sleep deprivation induced anxiety-like behaviour in mice.

\section{METHODS}

\begin{abstract}
Animals
Male Albino mice $(22.0 \pm 2.0 \mathrm{~g})$ used for this study were bred in the College of Health Sciences' Animal House, Delta State University, Abraka. These animals were allocated into five (5) treatment groups $(n=5)$ consisting of 6 animals each. Balanced rodent pellet and water was provided ad libitum. The experiment was performed in the Pharmacology laboratory of the affiliated institution from March 2020 to June 2020. The experimental methods were performed in accordance with the experimental guidelines of the National Institute of Health (NIH).
\end{abstract}

\section{Treatment schedule}

Group 1 was the naive group in which animals were not subjected to sleep deprivation and received only vehicle (i.e. distilled water $10 \mathrm{ml} / \mathrm{kg}$ ).

Group2 was the control group in which animals were subjected to 72 hours sleep deprivation and received vehicle treatment $(10 \mathrm{ml} / \mathrm{kg})$.

Groups 3-4 received Centella lujica supplement in two different doses $(50 \mathrm{mg} / \mathrm{kg}$ and $100 \mathrm{mg} / \mathrm{kg})$.

Group 5 received astaxanthin $(50 \mathrm{mg} / \mathrm{kg})$ in addition to being sleep deprived.

The animals were treated for 7 days and began sleep deprivation from day 4. Drug administrations were via the oral route (i.e. p.o.).

\section{Sleep deprivation procedure}

Sleep deprivation was done using the multiple platforms over water model. This method was chosen based on the belief that the mice on the platforms will fall into the water at the onset of sleep. ${ }^{21}$ This is due to muscle relaxation usually associated with rapid eye movement (REM) sleep. Upon falling into the water, they wake up quickly and struggle to get back on the platform. As a result, their sleep is disrupted. All animals in the respective treatment groups (group 2-5) were subjected to sleep deprivation except for mice in group 1. At the end of the 72 hour sleep deprivation period, different behavioural phenotypes of the animals were assessed between 9:00 am and 12:00 noon.

\section{Behavioural phenotypes}

\section{Assessment of anxiety-like behaviour}

\section{Using the light/dark transition box}

Each mouse was placed in the light/dark transition box and the duration spent in each of the compartments (i.e. light compartment and dark compartment) was measured for 5 $\min$. 


\section{Using the elevated plus maze}

Each mouse was placed in the elevated plus maze (EPM) and the duration spent in each of the arms (i.e. open arm and closed arm), including the frequency spent in each arm was measured for $5 \mathrm{~min}$.

\section{Assessment of stereotypy behaviour}

The open field chamber was employed to assess stereotype behaviour (rearing and grooming) in the mice. Animals were taken directly from their home cage and placed individually into a transparent open field chamber for observation.

The behavioural components employed in this observational analysis were cumulative frequencies of rearing (the number of times a mouse stood on its hind limb in the free air or with its forelimbs against the wall of the chamber) and grooming (the total number of times a mouse performed the following actions: cleaned its body with paws, picking its body and pubis area with mouth, and face washing actions), respectively. These behaviours were recorded for each mouse over a 10 min period. ${ }^{22}$

\section{Assessment of locomotor activity}

\section{Using the open field test}

The open field test (OFT) was employed to determine spontaneous motor activity (SMA) of the mice. For $10 \mathrm{~min}$ duration, each mouse was placed at the centre of the activity cage and allowed to explore freely. The number of square lines crossed with all paws and duration of ambulation of each mouse was recorded. ${ }^{22}$

\section{Using the rota rod}

The Ugo basile automated rota rod device was used in this test. The rota rod test, which is designed to assess motor function of laboratory animals, requires that the animal maintained its equilibrium on a rod that rotated at a constant speed.

Briefly, each mouse was positioned on the rotating bar of the rota rod set at $5 \mathrm{rpm}$. The duration spent by a mouse on the rota rod before it falls, which is referred to as the latency of fall (LOF) was used as the index of motor function.

\section{Preparation of brain tissues for histology}

After the behavioural tests, mice in the respective groups were euthanized. Thereafter, mice were perfused and their brains were harvested, and fixed with $10 \%$ phosphate buffered formaldehyde. Paraffin wax embedded-tissue blocks was obtained for each extracted mouse brain. About 5-6 $\mu \mathrm{m}$ thick transverse sections of the brains were obtained using a microtome (Leica, Germany) and the sections were fixed on glass slides.

\section{Histology and approximation of neuronal density}

Representative brain tissue sections of each treatment group were stained with Hematoxylin and Eosin (H\&E) to evaluate general histology of the striatum. Thereafter, the stained sections were viewed under a microscope (Olympus BX-51 binocular) at 400X magnification for evaluating the striatum of the brain and photographed using a digital camera (Optronics) connected to a computer (MagnaFire interface) to obtain photomicrographs. The slides were analysed for morphological changes. The general structure of the peri-glomerular, pyramidal cell and granule cells were described using inter-reader variability. The number of viable neuronal cells was analysed using computer based image analysis (Image $\mathrm{J}$ at $400 \mathrm{X}$ or $250 \mathrm{X})$ at different microscopic fields. Viable neuronal cells were designated as round-shaped with cytoplasmic membrane-intact cells and without any nuclear condensation. Neuronal density was then estimated as a ratio of viable neuronal cell counts to square (sq) area of the view in a section.

\section{Statistical analysis}

All the values are presented as mean \pm standard error of mean (SEM). The data were analysed using one-way analysis of variance (1-way ANOVA) followed by Student's Newman-Keuls test. All statistical procedures were carried out to determine significance using Graph Pad InStat ${ }^{\circledR}$ Biostatistics software. The criterion for significance in all tests was set at $\alpha_{0.05}$

\section{RESULTS}

\section{Effect of Centella lujica on anxiety-like behaviour induced by sleep deprivation}

As shown in Table 1 and Figure 1 below, the parameters of anxiety measured in the open field test increased significantly in the sleep deprived group when compared with the naïve group. However, following pre-treatment with Centella lujica, these symptoms were attenuated.

Table 1: Effect of Centella lujica on anxiety-like behaviour induced by sleep deprivation in mice.

\begin{tabular}{|lll|}
\hline Treatment & $\begin{array}{l}\text { Number of } \\
\text { lines crossed }\end{array}$ & $\begin{array}{l}\text { Ambulation } \\
\text { (min) }\end{array}$ \\
\hline VEH $10 ~ \mathbf{~ m l / k g ~}$ & $143.70 \pm 8.19$ & $3.52 \pm 0.36$ \\
\hline VEH $10 ~ \mathbf{~ m / k g ~ + ~ S D ~}$ & $213.50 \pm 10.22^{\#}$ & $6.88 \pm 0.39^{\#}$ \\
\hline CLS 50 mg/kg + SD & $178.80 \pm 9.82^{*}$ & $4.34 \pm 0.33^{*}$ \\
\hline $\begin{array}{l}\text { CLS } 100 ~ \mathbf{~ g} / \mathbf{k g}+ \\
\text { SD }\end{array}$ & $166.30 \pm 10.61^{*}$ & $4.17 \pm 0.33^{*}$ \\
\hline AXT 50 $\mathbf{~ m g / k g + ~ S D ~}$ & $185.50 \pm 4.88^{*}$ & $5.09 \pm 0.29^{*}$ \\
\hline
\end{tabular}

Each result is expressed as mean \pm S.E.M of grouped mice; \#indicates significant difference $(\mathrm{p}<0.05)$ compared to the vehicle (non-sleep deprived) group; *indicates significant difference $(\mathrm{p}<0.05)$ compared to the vehicle + SD group; VEH - vehicle; CLS - Centella lujica supplement; AXT - Astaxanthin; SD sleep deprivation 


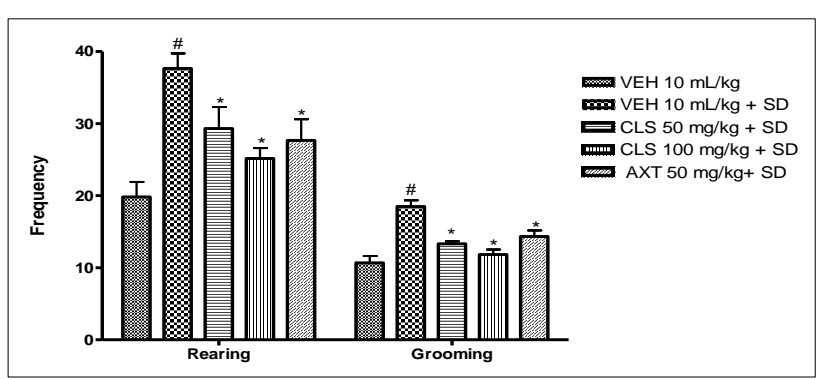

Figure 1: Rearing and grooming.

Sleep deprived mice were observed to spend more time in the dark compartment of the light/dark transition box compared to mice that were not sleep deprived. However significant changes were observed when Centella lujica was administered - the mice spent less time in the dark compartment and more time in the light compartment compared to the sleep deprived group (Figure 2).

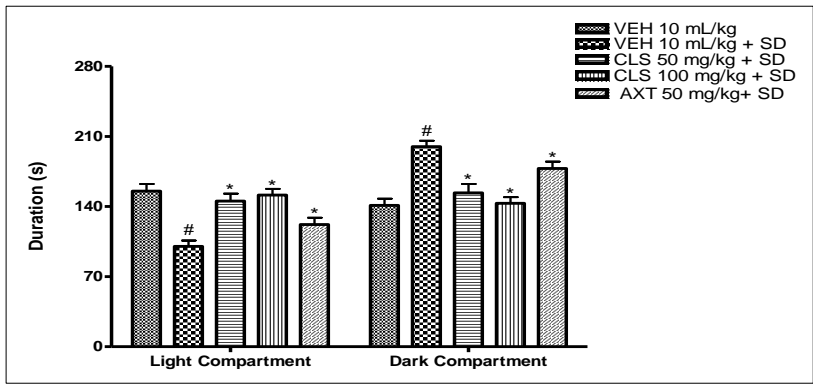

Figure 2: Effect of Centella lujica on anxiety in sleep deprived mice using the light/dark transition box.
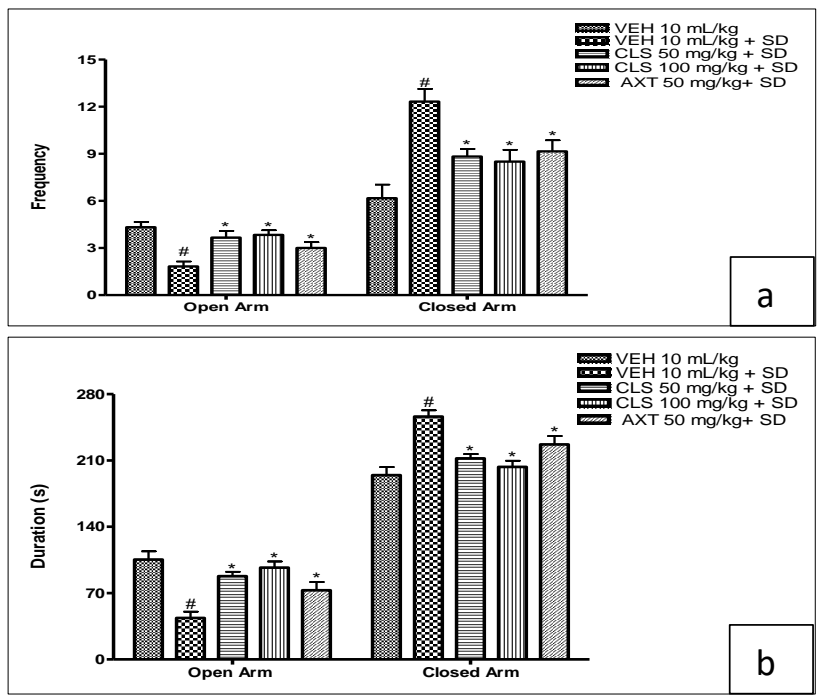

Figure 3: (a) and (b) Effect of Centella lujica on anxiety in sleep deprived mice using the elevated plus maze.

In the EPM, the sleep deprived mice were also observed to spend more time in the closed arm than the open arm; this is a classic indication of anxiety. However, the mice that received Centella lujica spent longer time in the open arm than closed arm, thus signifying that Centella lujica could possibly be used to attenuate the symptoms of anxiety associated with sleep deprivation (Figure $3 a$ and $b$ ).

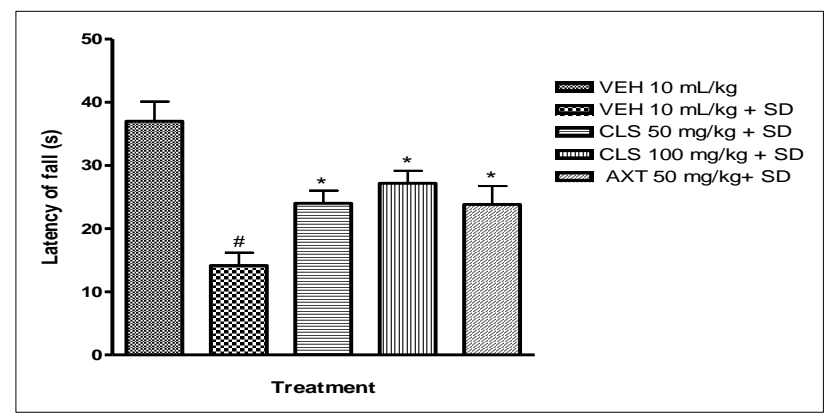

Figure 4: Effect of Centella lujica on motor coordination in mice subjected to sleep deprivation.

\section{Effect of Centella lujica on motor coordination in mice subjected to sleep deprivation}

The parameter of motor coordination was assessed using the rota rod. Figure 4 below shows that sleep deprivation for 72 hours significantly reduced the latency of fall as seen in sleep deprived group when compared with the naïve group. However, a significant increase in latency of fall was observed in the Centella lujica group.

\section{Effect of Centella lujica on the striatum of mice subjected to sleep deprivation}

Slide NC revealed normal neuronal cells devoid of any lesion, slide $\mathrm{N}$ revealed severe necrosis of the striatum neurons, slides G50 and G100 revealed normal cells with very mild diffuse gliosis, and slides AF1 revealed normal cells.

This finding revealed that sleep deprivation induced neuronal cell necrosis in the striatum which was reversed by Centella lujica administration. Furthermore, sleep deprivation significantly decreased the population of viable neuronal cells of the striatum when compared to the control, suggesting neurodegeneration (Figure 5). However, administration of Centella lujica at both doses attenuated this loss.

\section{Effect of Centella lujica on striatum neurons in sleep- deprived mice}

As seen in Figure 6, REM sleep deprivation for 72 hours significantly decreased total neuronal cell density of striatum neurons as seen in sleep deprived group when compared to naïve group. A significant restoration in total neuronal cell density of striatum neurons was however observed in the Centella lujica group.

Hematoxylin and Eosin (H\&E) staining revealed neuropathological changes in the striatum of mice exposed to sleep deprivation (Figure 5). 


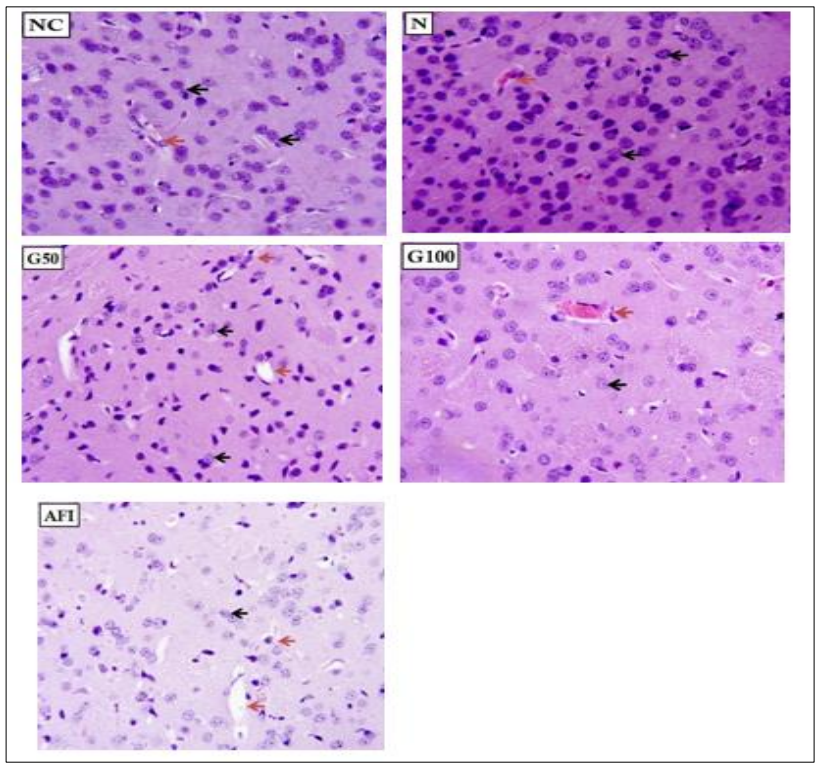

Figure 5: Photomicrograph of the striatum of mice subjected to sleep deprivation.

$\mathrm{NC}$ - vehicle only. N -Vehicle+SD; G50 - CLS $50 \mathrm{mg} / \mathrm{kg}+\mathrm{SD}$; G100 - CLS 100 mg/kg+SD; AF1 - AXT 50 mg/kg+SD; black arrow: normal neuronal cells; red arrow: neuronal cells undergoing necrosis; magnification: (X400)

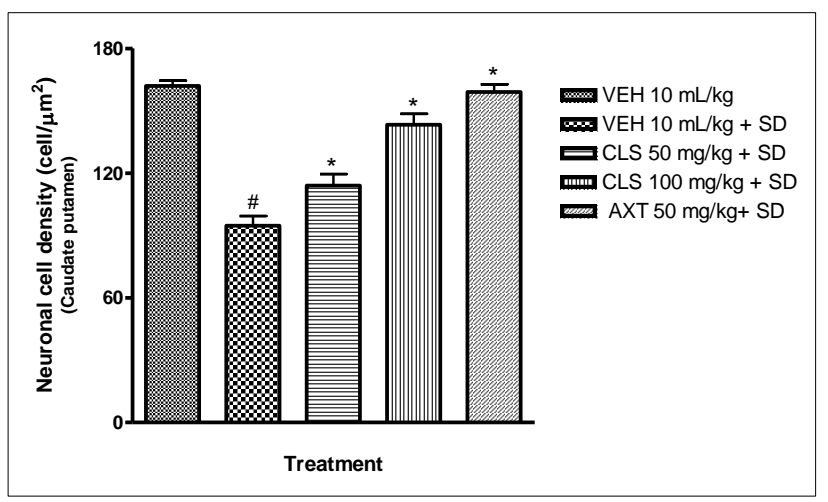

Figure 6: Effect of Centella lujica on viable striatum neurons in mice exposed to sleep deprivation.

Neuronal cell counts are based on the number of neuronal nuclei in three (3) rectangular boxes in each slide, using the precalibrated Image $\mathbf{J}$ software

\section{DISCUSSION}

The results from the present study revealed that sleep deprivation is a relevant animal model of mania and anxiety. The sleep derived mice displayed behavioural alterations analogous to manic symptoms of bipolar disorder as evidenced by an increase in hyperactivity (increased duration of ambulation and number of lines crossed) and stereotype behaviour (rearing and grooming) in the open field test. The mice were treated with Centella lujica supplement for seven (7) days and beginning from the fourth day were subjected to a 72-hour sleep deprivation utilizing the multiple platform over water model. These findings concur with previous studies, which showed that sleep deprivation can induce manic-like behaviour in mice. ${ }^{11,23-25}$ This sleep deprivation model has provided convincing evidence that a relationship between sleep loss and the onset of mania in humans exists. Thus, insufficient sleep represents a reliable precursor of mania, and sleep deprivation increases the risk of switching from depression to mania. ${ }^{11,26}$ In line with previous studies, the present study showed that mice displayed enhanced locomotor activity immediately after 72 hours of sleep deprivation. $^{23}$ Since psychomotor agitation has been described as a cardinal feature of mania, hyper locomotion has been used as the primary outcome to assess manic-like behaviour. ${ }^{27}$ Centella lujica supplement however was found to reverse the hyperactivity as well as the increase in stereotype behaviour induced by sleep deprivation. This observed anxiolytic effect exhibited by Centella lujica may be partly due to the inhibition of cholecystokinin receptors $(\mathrm{CCKb})$, a group of G-protein coupled receptors which are alleged to be involved in mitigating anxiety. ${ }^{28}$

Sleep is an essential biological function, and stressors such as sleep deprivation have consequences for the brain, as well as for other body systems. ${ }^{29}$ Sleep disruption or sleep deprivation can trigger an episode in manic or hypomanic people; this was observed especially in bipolar disorder but also in unipolar depression. ${ }^{30}$ In addition, sleep disruption often precedes depression or manic relapses. ${ }^{31}$ The sleep deprivation model is highly significant to understanding the aetiology of bipolar disorder since alterations in sleepwake patterns severely affect people suffering from this disorder. In fact, the manic phase of this disorder is characterized by a distinct reduction in the need for sleep. ${ }^{32}$

Also in the present study, the mice were sacrificed on the seventh day after the behavioural tests, and the brains extracted for histological studies. Hematoxylin and Eosin (H\&E) staining of the striatum revealed that sleep deprivation increased the extent of striatum neuronal damage and subsequently decreased the population of viable neurons in mice brains. However, Centella lujica supplementation significantly reduced the extent of neuronal damage and also increased the population of viable neuronal cells in the sleep deprived mice. This supports an earlier study which posited that Centella lujica plays a neuroprotective role in neurodegenerative diseases such as Alzheimer's disease. ${ }^{17}$

Taken together, Centella lujica can be considered a potential therapeutic agent for the treatment of anxiety or manic-like behaviour associated with sleep deprivation. However, the establishment of dosage, safety, tolerability and efficacy of Centella lujica supplement should be addressed in additional studies with different design approaches using other animal models of mania.

Although the results from this study augment the existing knowledge on Centella lujica and its potential benefit in neurobehaviors, the study was limited by time due to the worldwide imposed lockdown due to the global COVID19 pandemic which started while the research was ongoing. 


\section{CONCLUSION}

Based on the results from this research, Centella lujica has proven to possess a considerably significant activity against neurobehavioral deficits caused by sleep deprivation and could be beneficial for the management of mood related disorders.

\section{ACKNOWLEDGEMENTS}

Authors would like to thank technologists of the laboratory of Pharmacology department, Delta State University, Abraka.

\section{Funding: No funding sources}

Conflict of interest: None declared

Ethical approval: The study was approved by the Institutional Ethics Committee

\section{REFERENCES}

1. Kalonia H, Kumar A. Protective effects of melatonin on certain behavioural and biochemical alterations induced by sleep-deprivation in mice. Indian $\mathbf{J}$ Pharmacol. 2007;39:48-51.

2. Arias-Carrion OS, Huitron-Resendiz G, ArankowskySandoval, Murillo-Rodriguez E. Biochemical modulation of the sleep-wake cycle: endogenous sleep-inducing factors. J Neurosci Res. 2011;89(8):1143-9.

3. Banks S, Dinges DF. Behavioural and physiological consequences of sleep restriction. J Clin Sleep Med. 2007;3:519-28.

4. Colrain IM. Sleep and the brain. Neuropsychol Rev. 2011;21(1):1-4.

5. Rasch B, Born J. About sleep's role in memory. Physiol Rev. 2013;93:681-766.

6. Mathangi DC, Shyamala R, Subhashini AS. Effect of REM sleep deprivation on the antioxidant status in the brain of Wistar rats. Ann Neurosci. 2012;19:161.

7. Martins PJF, Nobrega JN, Tufik S, D'Almeida V. Sleep deprivation-induced gnawing-relationship to changes in feeding behaviour in rats. Physiol Behav. 2008;93:229-34.

8. Hagewoud RR, Havekes PA, Tiba A, Novati K, Hogenelst P, Weinreder, et al. Coping with sleep deprivation: shifts in regional brain activity and learning strategy. Sleep. 2010;33:1465-73.

9. Soto-Rodriguez S, Lopez-Armas G, Luquin S, RamosZuñiga R, Jauregui-Huerta F, Gonzalez-Perez O, et al. Rapid Eye Movement Sleep Deprivation Produces Long-Term Detrimental Effects in Spatial Memory and Modifies the Cellular Composition of the Subgranular Zone. Front Cell Neurosci. 2016;10:132.

10. Ramanathan LS, Gulyani R, Nienhuis JM. Sleep deprivation decreases superoxide dismutase activity in rat hippocampus and brainstem. Neuroreport. 2002;13(11):1387-90.

11. Salvadore G, Quiroz JA, Machado-Vieira R, Henter ID, Manji HK, Zarate CA. The Neurobiology of the
Switch Process in Bipolar Disorder: a Review. J Clin Psychiatr. 2010;71(11):1488-501.

12. Turk C, Lerner J, Heinberg RG, Rapee RM. An integrated cognitive-behavioural model of social anxiety. Hofmann SG, DiBartolo PM, Editors. Social anxiety to social phobia: Multiple perspectives. MA: Allyn \& Bacon. 2011;281-303.

13. Dement W. The effect of dream deprivation. Science. 1960;131:1705-7.

14. Bystritsky A, Khalsa SS, Cameron ME, Schiffman J. Current diagnosis and treatment of anxiety disorders. P T. 2013;38(1):30-57.

15. Wattanathorn J, Lugkana M, Supaporn M, Terdthai T, Orapin P, et al. Positive modulation of cognition and mood in the healthy elderly volunteer following the administration of Centella asiatica. J Ethnopharmacol. 2007;325-32.

16. Soumyanath A, Zhong Y, Henson E, Wadsworth T, Bishop J, et al. Centella asiatica extract improves behavioural deficits in a mouse model of Alzheimer's disease: investigation of a possible mechanism of action. Int J Alzheimers Dis. 2012;1-9.

17. Cooper EL, Ma MJ. Alzheimer Disease: Clues from traditional and complementary medicine. J Trad Complement Med. 2017;7(4):380-5.

18. Antognoni F, Perellino NC, Crippa S, Dal Toso R, Danieli B, Minghetti A, Poli F, Pressi G. Irbic acid, a dicaffeoylquinic acid derivative from Centella asiatica cell cultures. Fitoterapia. 2011;82(7):950-4.

19. Mato L, Wattanathorn J, Muchimapura S, Tongun T, Piyawatkul N, et al. Centella asiatica Improves Physical Performance and Health-related Quality of Life in Healthy Elderly Volunteer. Evid Based Compliment Alternat Med. 2009;1-7.

20. Chong J, Aziz Z. A systematic review of the efficacy of Centella asiatica for improvement of the signs and symptoms of chronic venous insufficiency. Evid Based Compliment Alternat Med. 2013;11:1-10.

21. Ajonijebu DC, Olayanju AO, Eduviere AT, Adewumi FA, Atodo KU, Akinsanya BT, et al. Effects of Calcitriol Supplementation on the Hematological Parameters of Sleep Deprived Wistar Rats. Int J Health Sci Res. 2016;6(3):127-34.

22. Adeoluwa OA, Aderibigbe AO, Agu GO, Adewole FA. Eduviere. Neurobehavioral and analgesic properties of ethanol bark extract of Terminalia ivorensis a Chev. (Combrataceae) in mice. Drug Res. 2015;65:545-51.

23. Gessa GL, Pani L, Fadda P, Fratta W. Sleep deprivation in the rat: an animal model of mania. Eur J Neuropsychopharmacol. 1995;5:89-93.

24. Malkoff-Schwartz SE, Frank B, Anderson JT, Sherrill L, Siegel D, et al. Stressful life events and social rhythm disruption in the onset of manic and depressive bipolar episodes: a preliminary investigation. Arch Gen Psychiatr. 1998;55:702-7.

25. McClung CA. Circadian genes, rhythms and the biology of mood disorders. Pharmacol Therap. 2007;114:222-32. 
26. Plante DT, Winkelman JW. Sleep disturbance in bipolar disorder: therapeutic implications. Am J Psych. 2008;165:830-43.

27. Young JW, Minassian A, Paulus MP, Geyer MA, Perry W. A reverse translational approach to bipolar disorder: rodent and human studies in the Behavioural Pattern Monitor. Neurosci Biobehav Rev. 2007;31:882-96.

28. Izumi T. Behavioural and neurochemical study on the role of the brain cholecystokinin system in anxiety. Hokkaido Igaku Zasshi. 1998;73(5):463-73.

29. McEwen BS. Sleep deprivation as a neurobiologic and psychologic stressor: allostasis and allostatic load. Metabolism. 2006;55:20-3.

30. Wehr T. Effects of wakefulness and sleep on depression and mania. Mountplaisir J, Godbout R, Editors. Sleep and biological rhythms: basic mechanisms and applications to psychiatry. Oxford University Press, Oxford. 1990;42-86.
31. Hudson JI, Lipinski JF, Keck PE, Aizley HG, Lukas SE, Rothschild AJ, et al. Polysomnographic characteristics of young manic patients. Comparison with unipolar depressed patients and normal control subjects. Arch Gen Psychiatry. 1992;49:378-83.

32. Berns GS, Nemeroff CB. The neurobiology of bipolar disorder. Am J Med Genet C Semin Med Genet. 2003;123C:76-84.

Cite this article as: Eduviere AT, Awhin PE, Edje KE, Otomewo LO, Moke EG, Omogbiya AI, et al. Pharmacological investigations of neuroprotective potential of Centella lujica supplement on sleep deprivation-induced anxiety-like behaviour in mice. Int J Basic Clin Pharmacol 2021;10:1227-33. 